\title{
REVIEW
}

\section{RNA interference-based therapeutics for shrimp viral diseases}

\author{
P. Krishnan, P. Gireesh-Babu*, K. V. Rajendran, Aparna Chaudhari \\ Central Institute of Fisheries Education, Indian Council of Agricultural Research, Seven Bungalows, Andheri West, \\ Versova, Mumbai-400061, India
}

\begin{abstract}
RNA interference (RNAi) has emerged as a powerful tool to manipulate gene expression in the laboratory. The presence of a double-stranded RNA (dsRNA) in eukaryotic cells triggers this post-transcriptional gene-silencing mechanism, leading to a sequence-specific degradation of the target mRNA. Among its many potential biomedical applications, silencing of viral genes stands out as a promising therapeutic strategy. Marine shrimp viral diseases, especially white spot disease (WSD), represents one of the most attractive targets for the development of therapeutic RNAi owing to its widespread economic impact. This review summarizes the current knowledge in the therapeutic application of RNAi for combating viral diseases in shrimp. The basic principles of RNAi are described, focusing on features important for its therapeutic manipulation. Subsequently, a stepwise strategy for the development of therapeutic RNAi is presented.
\end{abstract}

KEY WORDS: RNAi therapy $\cdot$ Shrimp diseases $\cdot$ Small interfering RNA $\cdot$ siRNA $\cdot$ Long hairpin RNA • lhRNA

\section{INTRODUCTION}

RNA interference (RNAi) is rapidly becoming a powerful tool for gene silencing (Voorhoeve \& Agami 2003). Even though the mechanism by which RNAi operates is not yet completely understood, many researchers are taking advantage of this phenomenon in different ways. The rapid production of knockdown animals where genes of interest have been selectively silenced is just one of many possible uses for RNAi (Voorhoeve \& Agami 2003). Another obvious use for RNAi is the selective silencing of viral genes essential for virulence (Shuey et al. 2002). This application would be particularly useful for developing effective viral vaccines for use among economically important invertebrate species which do not possess an adaptive immune system. This review summarizes the current status and future strategies concerning the therapeutic application of RNAi to combat viral diseases in shrimp.

\section{Viral diseases in shrimp}

Farm-raised shrimp account for 3 to $4 \%$ of global aquaculture production by weight and $15 \%$ by value (Rönnbäck 2001) with export earnings in the order of billions of US dollars per year. In the early 1990s, there was a series of viral outbreaks in various parts of the shrimp-producing world that crippled shrimp farmers across the globe. Lundin (1996) estimated that around $40 \%$ of the worldwide shrimp production, representing a value over $\$ 3$ billion, was lost due to infectious diseases. The main contributors to these losses are viral diseases. Of the 20 shrimp viruses known today, 6 are especially important due to their epizootic spread and economic impact: monodon baculovirus (MBV), infectious hypodermal and hematopoietic necrosis virus (IHHNV), Taura syndrome virus (TSV), yellow head virus (YHV), monodon slow growth syndrome (MSGS) and white spot syndrome virus (WSSV). All these viruses, with the 
exception of MSGS, are classified as OIE notifiable (OIE 2006). Among these, WSSV has had the greatest impact on shrimp farming and is currently considered the most important shrimp disease in terms of distribution and economic losses.

\section{Current therapeutic strategies}

Managing viral diseases has been the greatest challenge to the shrimp industry because short-term strategies, such as the use of immunostimulants, bioremediators and probiotics, have their own limitations in terms of their efficacy, practicability, cost, and, above all, reproducibility. Unlike finfishes, the shrimps lack a developed adaptive immune system, which is a prerequisite for the development of any protein vaccines. Subunit vaccines (Witteveldt et al. 2004a,b, 2006) have been reported to provide some degree of protection to shrimps from viral infection, but their field level potential is yet to be seen. In this scenario, RNAi, which seems to offer great promise in terms of treating human and animal diseases, is looked upon with great hope by shrimp health managers.

\section{ENDOGENOUS RNAi PATHWAY}

Observations were made in plants (Napoli et al. 1990, van der Krol et al. 1990) and nematodes (Lee et al. 1993), which hinted at the existence of the RNAi pathway years before double-stranded RNA (dsRNA) molecules were identified as the key component of this evolutionarily conserved post-transcriptional silencing pathway in eukaryotic cells (Fire et al. 1998). Since then, we have witnessed significant advances in the understanding of how RNAi functions and identified several effective ways to manipulate it in the laboratory. Although a detailed account on the mechanistic aspects of RNAi is beyond the scope of this review and can be found elsewhere (Bartel 2004, Carmell \& Hannon 2004, Cullen 2004, Meister \& Tuschl 2004, Murchison \& Hannon 2004, Du \& Zamore 2005, Kim 2005, Tomari \& Zamore 2005a,b), a brief description follows on our current knowledge of how RNAi operates, focusing on features that are important for the design of RNAi-based therapeutic molecules.

\section{Basic mechanism}

RNAi is a naturally occurring, post-transcriptional process by which dsRNA induces degradation of homologous mRNA transcripts (Fig. 1). The process is initially triggered when dsRNAs are expressed or introduced into a cell. Upon entering the cytoplasm, they act as substrate for the multidomain ribonuclease III enzyme, Dicer (Hammond et al. 2000), which cleaves dsRNA into 21 to 23 nucleotide (nt) fragments with characteristic 2-nt 3'overhangs. Referred to as small interfering RNAs (siRNAs), these distinctive dsRNA fragments confer sequence specificity in subsequent mRNA-degradation steps.

After cleavage by Dicer, siRNAs are recognized by the RNA-induced silencing complex (RISC) (Martinez et al. 2002), a multienzyme unit that binds and unwinds the double-stranded siRNAs. The sense strand of unwound siRNA is released, and in some organisms may trigger further dsRNA synthesis by RNA-dependent RNA polymerase (RdRp). The antisense siRNA remains bound to RISC, acting as a targeting sequence for the enzyme complex. When the RISC binds a homologous mRNA, it exerts nuclease activity and cleaves the target mRNA strand. The dam-

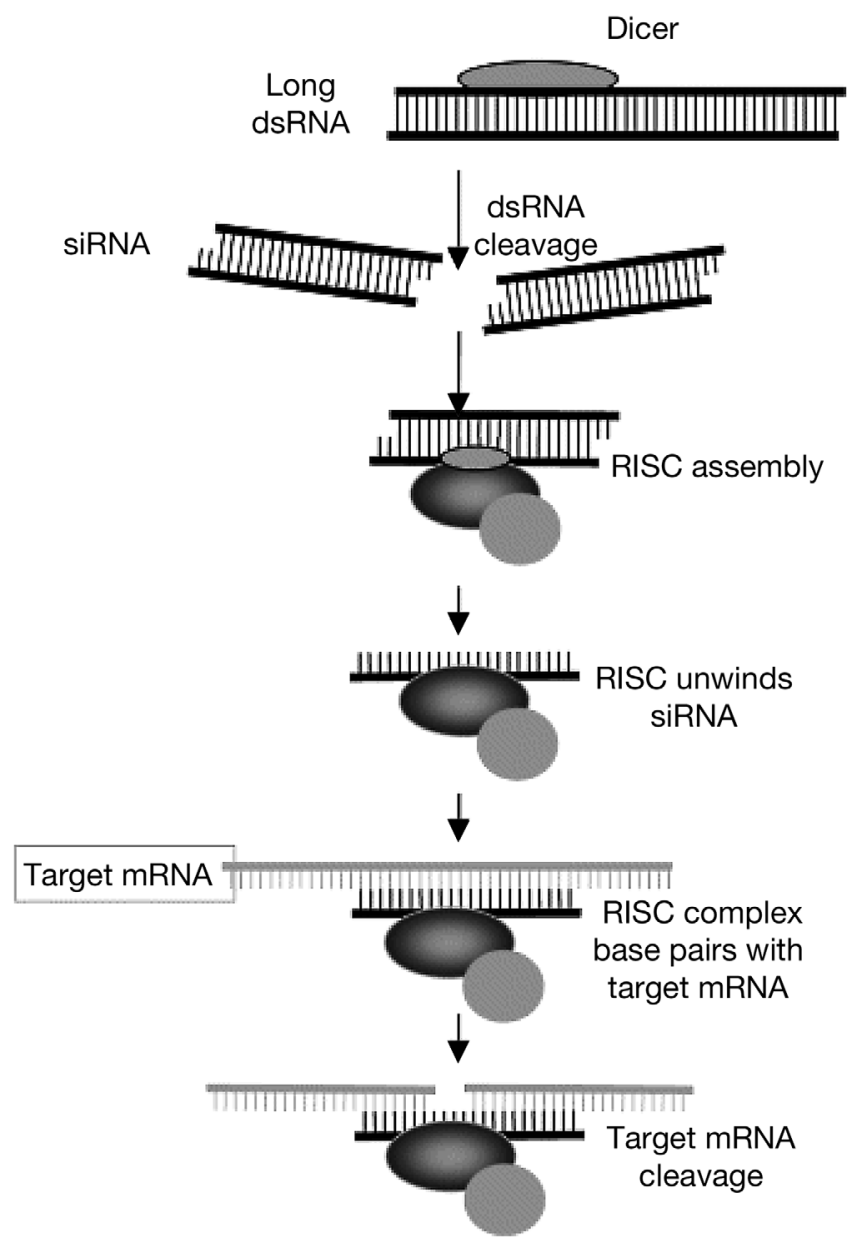

Fig. 1. Simple schematic of the RNA interference mechanism. Dicer: multidomain ribonuclease III enzyme; dsRNA: doublestranded RNA; siRNA: small interfering RNA; RISC: RNA-induced silencing complex 
aged mRNA is then degraded by the cellular machinery, resulting in sequence-specific, post-transcriptional gene silencing.

\section{RNAi as a therapeutic tool}

Among the many applications of RNAi, therapeutic silencing of disease-causing genes has received maximum attention. Gonzalez-Alegre (2007) has reviewed the extensive studies done on RNAi-based therapies for neurodegenerative diseases such as Alzheimer's disease, Parkinson's disease, and Huntington's disease. It has been used to check the expression of multiple drug resistance (MDR) protein that makes cancer cells resistant to chemotherapy (Wu et al. 2003, Yague et al. 2004). RNAi has been found to be a handy tool to control a number of viral diseases infecting humans and farmed animals. Apart from HIV-1, 25 different RNA viruses and 11 different DNA viruses have been effectively targeted by RNAi (Haasnoot et al. 2007). Usually, the viral structural proteins or polymerases are targeted for silencing. Promising results have been reported against HIV (Novina et al. 2002), Hepatitis A (Kusov et al. 2006) and B (Shlomai \& Shaul 2003) in humans and foot-and-mouth-disease virus in cattle (Chen et al. 2006a). Several RNAi-based drugs for human diseases are currently in the pre-clinical development stage and phase I or II clinical trials (www. sirna.com, www.acuitypharma.com). Wong et al. (2007) summarized the significance of nucleic acid-based antiviral drugs against seasonal and avian influenza virus in light of the fact that these viruses undergo consistant genetic change, which in part enable them to develop resistance to antiviral drugs and vaccines.

\section{Current status of RNAi to combat shrimp viral diseases}

Shrimps have been shown to produce non-specific anti-viral proteins (Pan et al. 2005). Plasma from surviving WSSV-infected shrimps, for instance, could neutralize WSSV from $20 \mathrm{~d}$ to 2 mo after infection. Various strategies to control WSSV have been tried including subunit vaccines (Witteveldt et al. 2004a,b) and DNA vaccination (Rout et al. 2007). However, being invertebrates, shrimps lack a true adaptive immune response system and these methods offer only limited protection.

Hence, RNA interference aimed at destroying the mRNA of crucial viral proteins and, thus, inhibiting the production of viable virions is an attractive alternative strategy (Plasterk 2002, Gitlin et al. 2002). RNAi has been shown to be effective against several viral infec- tions (Lecellier \& Voinnet 2004, Tan \& Yin 2004). It is possible to achieve the degradation of target mRNA by using antisense RNA, dsRNA or siRNA. Integral to this process is the type III endonuclease, Dicer, which is responsible for cleavage of long dsRNA/hairpin RNAs into siRNAs. The full length cDNA sequence encoding a Dicer-1 protein from Penaeus monodon has recently been reported (Su et al. 2007).

Tirasophon et al. (2005) demonstrated that dsRNA administered to a primary lymphoid cell culture (Oka cell) of black tiger shrimp gave protection against YHV infection. Injection of dsRNA induced resistance to WSSV and TSV in Pacific white shrimp Litopenaeus vannamei (Robalino et al. 2004). Yodmuang et al. (2006) reported that systemic and dose-dependent inhibition of YHV infection is possible in Penaeus monodon by administering specific dsRNA and that the efficiency of treatment would last for $5 \mathrm{~d}$. A similar observation has been made by Robalino et al. (2004, 2005) in experiments on L. vannamei. In vitro-transcribed long dsRNA corresponding to viral genes $v p 28$, vp281 and protein kinase, when administered prophylactically to Fenneropenaeus chinensis up to $3 \mathrm{~d}$ before viral challenge, yielded a survival of 100, 53 and $93 \%$, respectively (Kim et al. 2007). A long dsRNA could generate a more diverse pool of effective siRNAs incorporated into RISC than the shorter ones (Tirasophon et al. 2005). Westenberg et al. (2005) demonstrated that injection of siRNAs induces sequence-independent protection in $P$. monodon against WSSV. It is also possible to design specific siRNA that will be synthesized inside shrimp cells. Lu \& Sun (2005) produced a transgenic TSV-resistant L. vannamei that expresses an antisense RNA corresponding to a fragment of the TSV coat protein. These transgenic shrimp were found to be partially resistant to TSV infection.

Tirasophon et al. (2007) reported that administration of the YHV-specific dsRNA to infected shrimps within $12 \mathrm{~h}$ of the onset of infection completely abrogated the viral multiplication and prevented shrimp mortality, which suggested that, apart from being used as a preventive measure, RNAi could be used in curative modes too. $\mathrm{Xu}$ et al. (2007) reported that 3 successive injections of $v p 28$-siRNA at 0,24 and $48 \mathrm{~h}$ post challenge would completely eradicate WSSV in juvenile Penaeus japonicus.

\section{DEVELOPING THERAPEUTIC RNAi}

There are 3 broad stages in developing a RNAibased therapy for viral diseases: design, synthesis and delivery. In each of these broad stages, one has to consider a number of specific details in order to develop an efficient RNAi-based therapy. 


\section{Target gene}

The target gene is an essential factor in RNAi therapy. The target viral gene, when suppressed, should inhibit viral spread without causing any deleterious effect on the host organism. In order to manage viral escape, host factors that are essential for viral replication can also be targeted, as reported by Zhou et al. (2004) in HIV-1, provided it does not affect the host cell viability. To date, in shrimps, RNAi-based therapies have proved feasible against WSSV, YHV and TSV.

The WSSV structural genes that have been targeted for silencing so far by RNAi technology include $v p 15$ (Westenberg et al. 2005), vp19 (Robalino et al. 2004, 2005, Krishnan et al. 2009), vp28 (Westenberg et al. 2005, Kim et al. 2007, Xu et al. 2007, Krishnan et al. 2009) and vp281 (Kim et al. 2007). YHV genes that have been used as the targets for RNAi-based gene silencing trials are protease (Tirasophon et al. 2005, 2007, Yodmuang et al. 2006), RNA polymerase (Yodmuang et al. 2006), helicase and RdRP (Tirasophon et al. 2005).

In the above studies, gene expression was significantly reduced in all of the genes chosen, but comparable silencing with non-specific sequences was also achieved (Robalino et al. 2005, Kim et al. 2007). Green fluorescent protein and duck immunoglobulin genes have been used to study non-specific silencing in these studies (Robalino et al. 2005, Tirasophon et al. 2005). This has added merit to the hypothesis that dsRNA induces both sequence-specific as well as non-specific immunity in shrimps, though the former is more pronounced (Robalino et al. 2005, 2007).

\section{Target sequence}

After identifying the target gene, a specific sequence within that target gene has to be identified for effective silencing. To genarate a shortlist of candidate target sequences, the following broad guidelines should be employed: (1) the uniqueness of the sequence should be confirmed by performing BLAST; $(2)$ the sequence must be conserved among different strains reported for a particular virus; and (3) the selected sequence must have an optimal thermodynamic profile for incorporation as a guide strand into the RISC. In spite of all precautions, some sequences may lead to unexpected toxicity in vivo and so a pragmatic approach would be to screen 4 to 5 sequences for each gene before choosing the most effective therapeutic construct for in vivo trials. It is important to note that a mutation in a target gene can lead to loss of sensitivity to RNAi (Leonard \& Schaffer 2006) and RNA viruses accumulate point mutations up to $10^{7}$-fold more rapidly than DNA viruses (Drake et al. 1998).

\section{Effective design}

The siRNA must be effectively designed so as to target hybridization-accessible sites within the target mRNA while avoiding unintended effects. A combination of computer algorithms and empirical testing must be employed to define potent siRNAs, as not all immune-stimulatory RNA motifs have been identified yet. Detailed design criteria for optimal RNAi constructs (siRNA, and short or long hairpin RNA [sh- or lhRNA, respectively]) are available (Elbashir et al. 2001, Reynolds et al. 2004). Many web tools for the purpose of designing optimal constructs are available free online. Almost all commercial suppliers of siRNA consumables provide online design service for free, while there are also exclusive programs designed for the purpose, such as E-RNAi (http://e-rnai.dkfz.de).

Apart from the sequence, the size of the RNAi molecule is also important as it influences the biological retention time and efficiency of silencing. There are very limited studies on the biological retention of RNAi molecules in shrimps. However, studies on mice models suggest that naked siRNA molecules are susceptible to glomerular filtration in the kidney and excretion in the urine. Naked siRNAs accumulate in the kidneys of mice and are detectable in the urine as early as 5 min after intra-venous (i.v.) injection, and this could be prevented to a greater extent by enhancing the size of RNAi molecule beyond the range of glomerular filtration by conjugating siRNA with delivery complexes (Van de Water et al. 2006). The complexes have to be more than $100 \mathrm{~nm}$ to avoid renal excretion and be taken up by the cells (Li \& Szoka 2007). It is worth noting that to achieve greater than $90 \%$ gene silencing, siRNA has to remain effective inside the cell for more than 3 times the half-life of the targeted protein (Akhtar \& Benter 2007).

\section{Therapeutic molecules}

Once the target sequence has been identified, several strategies can be employed to produce siRNA, shRNA, lhRNA or micro-RNA (miRNA) against the target gene that enter the RNAi pathway at different levels (Amarzguioui et al. 2005). Selection of a suitable molecule is based on genetic and clinical characteristics of the disease.

siRNA. These are modeled after the natural Dicer cleavage products. The in vitro synthesized siRNAs are $21 \mathrm{nt}$ long with 2-nt 3' overhangs (Elbashir et al. 2001). The key advantage with these molecules is that they avoid overloading of cellular elements and result in fewer non-specific side effects, apart from exerting greater control over the transfection agents. 
However, synthetic siRNAs are relatively unstable in vivo due to degradation by nucleases and require frequent doses (Gonzalez-Alegre 2007). Chemical modifications may enhance in vivo half-life but hamper siRNA activity.

shRNA. These are modeled after pre-miRNAs with a small apical loop and a 3' UU overhang and are designed as plasmids that express anti-viral short hairpin RNA from a pol III promoter (Paddison et al. 2002). shRNAs are translocated from the nucleus to the cytoplasm by Exportin-5 and further processed in the cytoplasm by cellular Dicer into functional siRNAs. They can be used for long-term silencing, inducible expression and tissue specific delivery. However, shRNAs induce the interferon response and stress responsive cellular machinery apart from providing a way for the virus to mutate and develop escape variants (Patrick et al. 2002).

lhRNA. These are similar to shRNAs except that they are larger and induce RNAi by intracellular expression of long hairpin RNAs. The most salient advantage of this molecule is that it can generate multiple siRNAs from a single precursor, which may prevent viral escape. It is worth mentioning here that while dsRNAs longer than $30 \mathrm{bp}$ induce an interferon response, these intra-cellularly expressed lhRNAs do not (Haasnoot et al. 2007) and, hence, provide an excellent therapeutic tool. The only risk incurred with these molecules is that, if their dosage is not standardized, they may choke the endogenous cellular RNAi pathway.

miRNA. They constitute the second generation of RNAi-mediating constructs based on the structure of existing miRNA (Stegmeier et al. 2005). Since they are processed as endogenous miRNA genes, they undergo both nuclear and cytoplasmic processing events.

\section{Synthesis of RNAi molecules}

siRNA molecules for silencing select shrimp viral genes can be chemically synthesized or generated through in vitro transcription (Tirasophon et al. 2005, Kim et al. 2007). Yodmuang et al. (2006) injected the bacterially expressed YHV-protease dsRNA for endogenous synthesis of siRNAs using the cellular RNAi pathway. siRNAs may also be synthesized by in vitro digestion of bacterially expressed long dsRNA with the Dicer enzyme. Plasmid constructs that express lhRNA in vivo have been employed to silence the vp19 and vp28 genes of WSSV in tiger shrimp Penaeus monodon (Krishnan et al. 2009). As discussed earlier, employing shRNA and lhRNA expression constructs for this purpose facilitates long-term silencing of the viral genes.

\section{Delivery strategies}

One of the most important considerations while designing siRNA-based therapy is the mode of delivery. Several delivery strategies have been developed for the efficient delivery of the RNAi molecules both in vivo and in vitro. Cationic delivery systems have been employed to provide a net positive charge to the nucleic acid drugs, which facilitates interaction with the negatively charged cell membrane. The siRNA delivery reagent complexes, used for in vitro experiments, are often specifically referred to as lipoplexes, dendriplexes and polyplexes depending on whether the vector used is a cationic lipid, dendrimer or polymer, respectively. Contrary to the earlier belief that the delivery systems are biologically and genomically inert (Kabanov 2006), it has been reported by Omidi et al. (2003, 2005) that cationic lipids and polymers can directly induce gene expression changes in biological systems that might have siRNA activity. Therefore, it is necessary to screen the delivery systems for their geno-compatibility so as to ensure that they do not induce off-target effects.

Though viral vectors are recognized as efficient delivery systems for nucleic acids, their use in shrimps is limited as they induce toxic immune responses (Kay \& Nakai 2003, Thomas et al. 2003) and run the risk of being randomly integrated into the host genome (Kay et al. 2001). Akhtar \& Benter (2007) have reviewed the non-viral systemic delivery strategies reported for higher animals, viz., hydrodynamic i.v. injection, cholesterol conjugates, and cationic delivery systems (cationic lipids, liposomes, polymers and dendrimers).

The localized in vivo delivery strategies of siRNA and nucleic acid drugs, such as intraocular delivery (Tolentino et al. 2004), intratumoral delivery (Leng \& Mixson 2005, Song et al. 2005) and intranasal delivery to lungs (Bitko et al. 2005), have no application in shrimps. However, in vivo delivery of nucleic acids into the muscles by electroporation as reported by (Golzio et al. 2005) offers promise for exploration in shrimps.

To date, RNAi-based therapeutic trials have been done on juvenile shrimps and the molecules have been directly administered into the abdominal segments by intramuscular injection (Robalino et al. 2005, 2007). However, there lies immense promise for the use of RNAi-based therapeutic molecules in shrimp hatcheries to 'clean-up' high value shrimp broodstock from viruses so that vertical transmission of viral infection can be prevented. In such applications, it is envisaged that the RNAi molecules may be employed along with various transfection agents in order to reduce the dosage required and ensure more efficient delivery into the cells. Delivery of these molecules through the oral route (Sarathi et al. 2007), though a cost-effective 
option, needs to be studied extensively owing to problems such as siRNA degradation and poor bioavailability from the gastro-intestinal tract.

\section{Transient vs. stable}

Cellular delivery of interfering RNA typically occurs by one of 2 methods: through synthetic RNA oligos or vector-mediated RNA delivery. The first option is to deliver synthetic naked siRNA molecules (Elbashir et al. 2001), which can provide rapid but transient suppression. Alternatively, plasmid or viral vector constructs may also be designed that induce cells to transcribe 2 complementary RNA molecules that will hybridize to generate an siRNA or shRNA that folds to yield a dicer substrate (McCaffrey et al. 2002). However, delivery of expression constructs can provide more sustained RNAi.

Transient transfection of RNAi molecules could be possible by transfection of synthetic siRNAs or plasmids encoding shRNAs for acute virus infections. The logic behind this approach is that if the peak viral load is reduced significantly, the disease symptoms may be averted and the virus would thereafter be cleared by the host immune system (Haasnoot et al. 2007). So far all trials to combat shrimp viral diseases have been done employing this strategy.

Stable transfection provides long-term RNAi treatment and this can be done by integrating the RNAi expression cassette into the genome of the shrimp, which enables a constant supply of intra-cellularly expressed antiviral shRNAs and lhRNAs. However, during prolonged exposure to shRNA, the virus may become resistant to the expressed siRNAs by developing escape variants. Lu \& Sun (2005) demonstrated TSV resistance in Litopenaeus vannamei through expression of a stable antisense TSV coat protein gene construct.

\section{DNA vector-based RNAi}

Choice of promoter. Generally pol III promoters such as U6 and H1 are used for expressing shRNA constructs, as they are more effective than pol II promoters. These promoters are compact, support high levels of transcription and initiate transcription at a defined starting point. They terminate transcription at runs of 4 or more thymidines in the DNA template, leaving 1 to 4 uridines at the $3^{\prime}$ of the transcribed RNA. H1 promoter is smaller than U6 and can initiate transcription at any site while U6 can only start at a 'G'. U6 and H1 are used in bidirectional promoter constructs and in shRNA stable expression constructs. Cytomegalovirus promoter (CMVp) cannot be used for shRNA vectors as they append 5' vector sequences and 3' poly AA sequences, which inhibit shRNA function, but are ideal for lhRNA constructs. Apart from CMV immediate early promoter, other pol II promoters that are suitable for lhRNA expression and known to be active in shrimps include $\beta$-actin and SV40 early promoters (Arenal et al. 2000).

In recent studies, promoters of the single whey acidic protein (WAP) domain-containing protein gene (Chen et al. 2006b) and EF-1 $\alpha$ gene (Yazawa et al. 2005) isolated from marine shrimps have been demonstrated to drive protein expression comparable to CMVp. In addition to these, a WSSV promoter (Immediate early ie1 promoter) has also been tested in shrimps (Liu et al. 2005, Lu et al. 2005).

Fate of the RNAi constructs in vivo. Tonheim et al. (2008) reviewed the fate of expression constructs injected intramuscularly in fish and summarized that plasmid DNA on injection enters the extracellular milieu of the administration site where it can be degraded, taken up by cells and/or transferred to the circulatory system and distributed to other organs/tissues. Robalino et al. (2005) suggest that dsRNA injected intramuscularly in the tail muscle of Litopenaeus vannamei probably travels via the circulation to different tissues; they hypothesized that internalization of exogenous DNA by shrimp cells in vivo could be through the cell surface receptors similar to those reported in nematodes (Winston et al. 2002) and fruit flies (Ulvila et al. 2006). The expression constructs have been shown to be retained and persistently expressed in different tissues of shrimps up to 2 mo after intramuscular injection in the tail muscle (Rout et al. 2007). Successful silencing of specific WSSV genes has been reported in shrimps through intramuscular injection of gene-specific siRNA (Kim et al. 2007, Sarathi et al. 2007) and dsRNA (Robalino et al. 2004, 2005, Westenberg et al. 2005).

\section{RNAi THERAPY: ISSUES AND CHALLENGES}

RNAi-mediated gene silencing, though highly efficient, relies on translational inhibition to disrupt gene expression. Thus, even though some genes can be reduced to less than $10 \%$ of wild-type levels, there will always be some 'leaky' expression of mRNA that escapes the RISC complex and is translated. A true null allele is possible only through traditional methods that knock out the gene at the DNA level. Although no restriction has been reported on the type of gene that can be silenced through RNAi, the degree of gene knockdown can vary from one gene to the next. A 50 to $90 \%$ reduction in gene activity is generally considered 
to be a successful knockdown (www.clontech.com). Optimizing the siRNA or shRNA sequence through careful design and validation can improve silencing efficiency.

\section{Off-target effects}

The specificity of RNAi is mostly theoretical and offtarget effects are one of the most critical issues limiting the scope of siRNA based therapeutics. The genomewide effect of each of the siRNAs is not known and is difficult to predict.

A majority of the experimentally verified off-targets have a 6 to $7 \mathrm{nt}$ match to the siRNA in the so-called 'seed' region (Lim et al. 2005, Birmingham et al. 2006, Jackson et al. 2006a). Jackson et al. (2003) demonstrated that a match between target and siRNA to the extent of $11 \mathrm{nt}$ could result in off-target knockdown. In some cases, even the transfection reagents have been shown to influence the expression profiles of the gene independent of siRNAs. In vitro studies on cell lines indicate that off-targeting affects cell viability and results in a toxic phenotype (Fedorov et al. 2006).

A number of strategies have been advocated by different researchers to combat the off-target effects in RNAi experiments. These include identifying potent or hyperfunctional siRNA that work at sub-nanomolar concentrations, introducing a 2' O-Me modification at the second base of siRNA (Jackson et al. 2006b), designing optimal siRNAs to prevent incorporation of passenger strand into the RISC (Schwarz et al. 2003) and introducing mismatches in the passenger strand to improve cleavage efficiency.

\section{Saturating endogenous RNAi pathways}

Exogenous RNAi therapeutic molecules rely on the cellular machinery in order to silence the target genes, which may affect the natural system. They are known to trigger abnormalities in hepatocytes (Grimm et al. 2006) and neurons (Alvarez et al. 2006), probably through saturation of specific steps of this pathway. Since shRNA and siRNA resemble miRNA precursors before and after Dicer processing, respectively, all components of the miRNA pathway might be clogged by high doses of ectopic RNA. Although our understanding of the natural role of RNAi in mammalian cells has expanded tremendously with the discovery of miRNAs, other facets of this highly conserved biological system are still to be unraveled (Aagaard \& Rossi 2007).

Some strategies to combat this issue include the use of siRNA against miRNA or shRNA, which would bypass some of the nuclear and cytoplasmic steps of
RNAi pathway, using siRNAs that are efficient at low doses and opting for a controllable or moderate promoter system while using a vector based shRNA expression system (Gonzalez-Alegre 2007).

\section{Viral escape mechanisms}

Viruses have evolved many mechanisms to escape RNAi, as they have for many antiviral drugs. The most common escape strategy is single-nucleotide substitution or deletion within the siRNA target sequence (Boden et al. 2003, Gitlin et al. 2005, Wilson \& Richardson 2005). An alternative escape mechanism has been reported in HIV-1 wherein a local RNA structure is induced to prevent the target sequence from binding to siRNA/RISC by selection of an upstream mutation (Westerhout et al. 2005). Viruses have also evolved proteins that actively interfere with distinct steps of RNAi machinery to ensure viral production and efficient viral spread (Li \& Ding 2006). The extent of the threat posed by these suppressors to RNAi-based therapeutics is not fully established. However, a number of recent studies showing RNAi-induced viral gene silencing corroborate that RNAi-based viral therapies are potential tools for disease management (Novina et al. 2002, Chen et al. 2006a, Kusar et al. 2006, Krishnan et al. 2009).

To design potent antiviral therapies, the local secondary structures of the target sequence must be analyzed. It is suggested that by employing multiple antiviral drugs, combined expression of multiple shRNAs or a single lhRNA that produces multiple antiviral siRNAs, viral replication may be completely blocked and the emergence of resistant variants may be prevented (ter Brake et al. 2006, Grimm \& Kay 2007). The added benefit of this strategy is that the virus would have to evolve mutations to multiple targets in order to escape RNAi and would lose virulence in the process. However, care is to be exercised that over-expression of multiple shRNAs neither saturates cellular RNAi pathways nor induces off-target effects. Cellular co-factors or the viral genes that express RNAi suppressors may also be targeted to make viral escape more difficult. In order to target viral RNA with protective protein or modified RNA structure, siRNAs with duplex invading properties may be employed so that they bind with high affinity to the target genes.

\section{CONCLUSION AND FUTURE DIRECTIONS}

It should be noted that the choice of delivery vehicle, route of administration, genes targeted and the regulation and duration of RNAi induction depend on the life cycle of the pathogen and, hence, due consideration 
should be paid to it while designing the RNAi-based therapy. Cellular delivery and stabilization are critical hurdles to overcome in the development of viable RNAi-based drugs. Effective gene silencing is a function of the charge and chemistry of nucleic acid drugs, delivery systems and the half-life of the target gene. There are still many issues to be addressed before RNAi therapy finds practical application in managing shrimp viral diseases. Basic information is essential to develop an efficient disease management program, e.g. information on the bio-distribution and biological stability of the RNAi molecules in shrimps, the transcription rate and half-life of the viral gene to be targeted, and the level of knockdown desired in order to curtail disease manifestation. As evidenced by recent research, it will be some time before the RNAi lives up to its promise for managing shrimp viral diseases.

\section{LITERATURE CITED}

> Aagaard L, Rossi JJ (2007) RNAi therapeutics: principles, prospects and challenges. Adv Drug Deliv Rev 59:75-86

Akhtar S, Benter IF (2007) Non-viral delivery of synthetic siRNAs in vivo. J Clin Invest 117:3623-3632

> Alvarez VA, Ridennour DA, Sabatini BL (2006) Retraction of synapses and dendritic spines induced by off-target effects of RNA interference. J Neurosci 26:7820-7825

Amarzguioui M, Rossi JJ, Kim D (2005) Approaches for chemically synthesized siRNA and vector mediated RNAi. FEBS Lett 579:5974-5981

Arenal A, Pimentel R, Guimarais M, Rodriguez A, Martinez R, Abad Z (2000) Gene transfer in shrimp (Litopenaeus schmitti) by electroporation of single cell embryos and injection of naked DNA into adult muscle. Biotecnol Apl $17: 247-250$

Bartel DP (2004) MicroRNA: genomics, biogenesis, mechanism, and function. Cell 116:281-297

Birmingham A, Anderson EM, Reynolds A, Ilsley-Tyree D and others (2006) 3' UTR seed matches, but not overall identity, are associated with RNAi off-targets. Nat Methods 3: 199-204

> Bitko V, Musiyenko A, Shulyayeva O, Barik S (2005) Inhibition of respiratory viruses by nasally administered siRNA. Nat Med 11:50-55

Boden D, Pusch O, Lee F, Tucker L, Ramratnam B (2003) Human immunodeficiency virus type 1 escape from RNA interference. J Virol 77:11531-11535

Carmell MA, Hannon GJ (2004) RNase III enzymes and the initiation of gene silencing. Nat Struct Mol Biol 11: $214-218$

> Chen W, Liu M, Jiao Y, Yan W and others (2006a) Adenovirusmediated RNA interference against foot-and-mouth disease virus infection both in vitro and in vivo. J Virol 80: 3559-3566

> Chen JY, Chen JC, Lin SH, Pani CY, Kuo CM (2006b) Organization and promoter analysis of a tiger shrimp, Penaeus monodon single WAP domain-containing protein gene. Fish Sci 72:1086-1095

> Cullen BR (2004) Transcription and processing of human microRNA precursors. Mol Cell 16:861-865

> Drake JW, Charlesworth B, Charlesworth D, Crow JF (1998) Rates of spontaneous mutation. Genetics 148:1667-1686
Du T, Zamore PD (2005) MicroPrimer: the biogenesis and function of microRNA. Development 132:4645-4652

Elbashir SM, Harborth J, Lendeckel W, Yalcin A, Weber K, Tuschl T (2001) Duplexes of 21-nucleotide RNAs mediate RNA interference in cultured mammalian cells. Nature 411:494-498

> Fedorov Y, Anderson EM, Birmingham A, Reynolds A and others (2006) Off-target effects by siRNA can induce toxic phenotype. RNA 12:1188-1196

Fire A, Xu S, Montgomery MK, Kostas SA, Driver SE, Mello CC (1998) Potent and specific genetic interference by double-stranded RNA in Caenorhabditis elegans. Nature 391: 806-811

> Gitlin L, Myers CP, Andino R (2002) siRNA confers intracellular antiviral immunity in human cells. Nature 418:430-434

Gitlin L, Stone JK, Andino R (2005) Poliovirus escape from RNA interference: short interfering RNA-target recognition and implications for therapeutic approaches. J Virol 79:1027-1035

> Golzio M, Mazzolini L, Moller P, Rols MP, Teissie J (2005) Inhibition of gene expression in mice muscle by in vivo electrically mediated siRNA delivery. Gene Ther 12: 246-251

Gonzalez-Alegre P (2007) Therapeutic RNA interference for neurodegenerative diseases: from promise to progress. Pharmacol Ther 114:34-55

Grimm D, Kay MA (2007) Combinatorial RNAi: A winning strategy for the race against evolving targets? Mol Ther 15:878-888

Grimm D, Streetz KL, Jopling CL, Storm TA, Pandey K, Davis CR (2006) Fatality in mice due to oversaturation of cellular microRNA/short hairpin RNA pathways. Nature 441: $537-541$

Haasnoot J, Westerhout EM, Berkhout B (2007) RNA interference against viruses: strike and counterstrike. Nat Biotechnol 25:1435-1442

Hammond SM, Bernstein E, Beach D, Hannon GJ (2000) An RNA-directed nuclease mediates post-transcriptional gene silencing in Drosophila cells. Nature 404:293-296

Jackson AL, Bartz SR, Schelter J, Kobayashi SV and others (2003) Expression profiling reveals off-target gene regulation by RNAi. Nat Biotechnol 21:635-637

Jackson AL, Burchard J, Leake D, Reynolds A and others (2006a) Position-specific chemical modification of siRNAs reduces 'off-target' transcript silencing. RNA 12:1197-1205

Jackson AL, Burchard J, Schelter J, Chau BN, Cleary M, Lim L, Linsley PS (2006b) Widespread siRNA 'off-target' transcript silencing mediated by seed region sequence complimentarity. RNA 12:1179-1187

Kabanov AV (2006) Polymer genomics: an insight into pharmacology and toxicology of nanomedicines. Adv Drug Deliv Rev 58:1597-1621

Kay MA, Nakai H (2003) Looking into the safety of AAV vectors. Nature 424:251

Kay MA, Glorioso JC, Naldini L (2001) Viral vectors for gene therapy: the art of turning infectious agents into vehicles of therapeutics. Nat Med 7:33-40

Kim VN (2005) MicroRNA biogenesis: coordinated cropping and dicing. Nat Rev Mol Cell Biol 6:376-385

Kim CS, Kosuke Z, Nam YK, Kim SK, Kim KH (2007) Protection of shrimp (Penaeus chinensis) against white spot syndrome virus (WSSV) challenge by double-stranded RNA. Fish Shellfish Immunol 23:242-246

Krishnan P, Gireesh BP, Saravanan S, Rajendran KV, Chaudhari A (2009) DNA constructs expressing long-hairpin RNA (lhRNA) protect Penaeus monodon against white spot syndrome virus. Vaccine 27:3849-3855 
Kusov Y, Kanda T, Palmenberg A, Sgro JY, Gauss-Muller V (2006) Silencing of Hepatitis A virus infection by siRNA. J Virol 80:5599-5610

Lecellier CH, Voinnet O (2004) RNA silencing: no mercy for viruses? Immunol Rev 198:285-303

Lee RC, Feinbaum RL, Ambros V (1993) The C. elegans heterochronic gene lin-4 encodes small RNA with antisense complementarity to lin-14. Cell 75:843-854

Leng Q, Mixson AJ (2005) Small interfering RNA targeting Raf-1 inhibits tumor growth in vitro and in vivo. Cancer Gene Ther 12:682-690

- Leonard JN, Schaffer DV (2006) Antiviral therapy: emerging approaches for hitting a moving target. Gene Ther 13: 532-540

Li F, Ding SW (2006) Virus counter defense: diverse strategies for evading the RNA-silencing immunity. Annu Rev Microbiol 60:503-531

Li W, Szoka FC Jr (2007) Lipid-based nanoparticles for nucleic acid delivery. Pharm Res 24:438-449

> Lim LP, Lau NC, Garrett-Engele P, Grimson A and others (2005) Microarray analysis shows that some microRNAs downregulate large numbers of target mRNAs. Nature 433:769-773

Liu WJ, Chang YS, Wang CH, Kou GH, Lo CF (2005) Microarray and RT-PCR screening for white spot syndrome virus immediate-early genes in cycloheximide-treated shrimp. Virology 334:327-341

Lu Y, Sun PS (2005) Viral resistance in shrimp that express an antisense TSV coat protein gene. Antiviral Res 67: $141-146$

Lu L, Wang H, Manopo I, Yu L, Kwang J (2005) Baculovirus-mediated promoter assay and transcriptional analysis of white spot syndrome virus orf427 gene. Virol J 2:71

Lundin GG (1996) Global attempts to address shrimp disease, Marine/Environmental Paper No. 4. Land, Water and Natural Habitats Division, Environment Department, The World Bank, Rome

- Martinez J, Patkaniowska A, Urlaub H, Luhrmann R, Tuschl T (2002) Single-stranded antisense siRNAs guide target RNA cleavage in RNAi. Cell 110:563-574

McCaffrey AP, Meuse L, Pham TT, Conklin DS, Hannon GJ, Kay MA (2002) RNA interference in adult mice. Nature 418:38-39

Meister G, Tuschl T (2004) Mechanisms of gene silencing by double-stranded RNA. Nature 431:343-349

Murchison EP, Hannon GJ (2004) miRNA on the move: miRNA biogenesis and the RNAi machinery. Curr Opin Cell Biol 16:223-229

Napoli C, Lemieux C, Jorgensen R (1990) Introduction of a chimeric chalcone synthase gene into petunia results in reversible co-suppression of homologous genes in trans. Plant Cell 2:279-289

> Novina CD, Murray MF, Dykxhoorn DM, Beresford PJ and others (2002) siRNA-directed inhibition of HIV-1 infection. Nat Med 8:681-686

OIE (2006) Manual of diagnostic tests for aquatic animals, 5th edn. Office International des Epizooties (OIE), Paris

Omidi Y, Hollins AJ, Benboubetra M, Drayton R, Benter IF, Akhtar S (2003) Toxicogenomics of non-viral vectors for gene therapy: a microarray study of lipofectin- and oligofectamine-induced gene expression changes in human epithelial cells. J Drug Target 11:311-323

Omidi Y, Hollins AJ, Drayton RM, Akhtar S (2005) Polypropylenimine dendrimer-induced gene expression changes: the effect of complexation with DNA, dendrimer generation and cell type. J Drug Target 13:431-443
Paddison PJ, Caudy AA, Bernstein E, Hannon GJ, Conklin DS (2002) Short hairpin RNAs (shRNAs) induce sequencespecific silencing in mammalian cells. Genes Dev 16: 948-958

Pan D, He N, Yang Z, Liu H, Xu X (2005) Differential gene expression profile in hepatopancreas of WSSV-resistant shrimp (Penaeus japonicus) by suppression subtractive hybridization. Dev Comp Immunol 29:103-112

Plasterk RHA (2002) RNA silencing: the genome's immune system. Science 296:1263-1265

> Reynolds A, Leake D, Boese Q, Saringe S, Marshal WS, Khvorova A (2004) Rational siRNA design for RNA interference. Nat Biotechnol 22:326-330

> Robalino J, Browdy CL, Prior S, Metz A and others (2004) Induction of antiviral immunity by double-stranded RNA in a marine invertebrate. J Virol 78:10442-10448

Robalino J, Bartlett TC, Shepard EF, Prior S and others (2005) Double-stranded RNA induces sequence-specific antiviral silencing in addition to nonspecific immunity in marine shrimp: convergence of RNA interference and innate immunity in the invertebrate antiviral response. J Virol 79:13561-13571

> Robalino J, Bartlett TC, Chapman RW, Gross PS, Browdy CL, Warr GW (2007) Double-stranded RNA and antiviral immunity in marine shrimp: Inducible host mechanisms and evidence for the evolution of viral counter responses. Dev Comp Immunol 31:539-547

Rönnbäck P (2001) Shrimp aquaculture - state of the art. Swedish EIA Centre, Report 1. Swedish University of Agricultural Sciences (SLU), Uppsala

Rout N, Kumar S, Jaganmohan S, Murugan V (2007) DNA vaccines encoding viral envelopeproteins confer protective immunity against WSSV in black tiger shrimp. Vaccine 25:2778-2786

Sarathi M, Simon MC, Ahmed VPI, Kumar SR, Sahul-Hameed AS (2007) Silencing VP28 gene of white spot syndrome virus of shrimp by bacterially expressed dsRNA. Mar Biotechnol 10:198-206

Schwarz DS, Hutvagner G, Du T, Xu Z, Aronin N, Zamore PD (2003) Asymmetry in the assembly of the RNAi enzyme complex. Cell 115:199-208

Shlomai A, Shaul Y (2003) Inhibition of Hepatitis B virus expression and replication by RNA interference. Hepatology 37:764-770

Shuey DJ, McCallus DE, Giordano T (2002) RNAi: genesilencing in therapeutic intervention. Drug Discov Today 7:1040-1046

Song E, Zhu P, Lee SK, Chowdhury D and others (2005) Antibody mediated in vivo delivery of small interfering RNAs via cell-surface receptors. Nat Biotechnol 23:709-717

Stegmeier F, Hu G, Rickles RJ, Hannon GJ, Elledge SJ (2005) A lentiviral microRNA-based system for single-copy polymerase II-regulated RNA interference in mammalian cells. Proc Natl Acad Sci USA 102:13212-13217

Su J, Oanh DTH, Lyons RE, Leeton L and others (2007) A key gene of the RNA interference pathway in the black tiger shrimp, Penaeus monodon: identification and functional characterisation of Dicer-1. Fish Shellfish Immunol 24: 223-233

Tan FL, Yin JQ (2004) RNAi, a new therapeutic strategy against viral infection. Cell Res 14:460-466

ter Brake O, Konstantinova P, Ceylan M, Berkhout B (2006) Silencing of HIV-1 with RNA interference: a multiple shRNA approach. Mol Ther 14:883-892

Thomas CE, Ehrhardt A, Kay MA (2003) Progress and problems with the use of viral vectors for gene therapy. Nat Rev Genet 4:346-358 
Tirasophon W, Roshorm Y, Panyim S (2005) Silencing of yellow head virus replication in penaeid shrimp cells by dsRNA. Biochem Biophys Res Comm 334:102-107

Tirasophon W, Yodmuang S, Chinnirunvong W, Plongthongkum N, Panyim S (2006) Therapeutic inhibition of yellow head virus multiplication in infected shrimps by YHVprotease dsRNA. Antiviral Res 74:150-155

Tolentino MJ, Brucker AJ, Fosnot J, Ying GS and others (2004) Intravitreal injection of vascular endothelial growth factor small interfering RNA inhibits growth and leakage in a nonhuman primate, laser-induced model of choroidal neovascularization. Retina 24:132-138

Tomari Y, Zamore PD (2005a) MicroRNA biogenesis: Drosha can't cut it without a partner. Curr Biol 15:R61-R64

Tomari Y, Zamore PD (2005b) Perspective: machines for RNAi. Genes Dev 19:517-529

Tonheim TC, Bogwald J, Dalmo RA (2008) What happens to the DNA vaccine in fish? A review of current knowledge. Fish Shellfish Immunol 25:1-18

Ulvila J, Parikka M, Kleino A, Sormunen R and others (2006) Double stranded RNA is internalized by scavenger receptor mediated endocytosis in Drosophila melanogaster S2 cells. J Biol Chem 281:14370-14375

Van de Water FM, Boerman OC, Wouterse AC, Peters JGP, Russel FGM, Masereeuw R (2006) Intravenously administered short interfering RNA accumulates in the kidney and selectively suppresses gene function in renal proximal tubules. Drug Metab Dispos 34:1393-1397

van der Krol AR, Mur LA, Beld M, Mol JN, Stuitje AR (1990) Flavonoid genes in petunia: addition of a limited number of gene copies may lead to a suppression of gene expression. Plant Cell 2:291-299

Voorhoeve PM, Agami R (2003) Knockdown stands up. Trends Biotechnol 21:2-4

Westenberg M, Heinhius B, Zuidema D, Vlak JM (2005) siRNA injection induces sequence independent protection in Penaeus monodon against white spot syndrome virus. Virus Res 114:133-139

> Westerhout EM, Ooms M, Vink M, Das AT, Berkhout B (2005) HIV-1 can escape from RNA interference by evolving an alternative structure in its RNA genome. Nucleic Acids Res 33:796-804

Wilson JA, Richardson CD (2005) Hepatitis C virus replicons

Editorial responsibility: Ken Hasson,

College Station, Texas, USA escape RNA interference induced by a short interfering RNA directed against the NS5b coding region. J Virol 79: 7050-7058

- Winston WM, Molodowitch C, Hunter CP (2002) Systemic RNAi in Caenorhabditis elegans requires the putative transmembrane protein SID-1. Science 295:2456-2459

> Witteveldt J, Cifuentes CC, Vlak JM, van Hulten MC (2004a) Protection of Penaeus monodon against white spot syndrome virus by oral vaccination. J Virol 78:2057-2061

Witteveldt J, Vlak JM, van Hulten MC (2004b) Protection of Penaeus monodon against white spot syndrome virus using a WSSV subunit vaccine. Fish Shellfish Immunol 16: 571-579

Witteveldt J, Vlak JM, van Hulten MCW (2006) Increased tolerance of Litopenaeus vannamei to white spot syndrome virus (WSSV) infection after oral application of the viral envelope protein VP28. Dis Aquat Org 70:167-170

> Wong JP, Christopher ME, Salazar AM, Dale RMK, Sun LQ, Wang M (2007) Nucleic acid-based antiviral drugs against seasonal and avian influenza viruses. Vaccine 25: 3175-3178

- Wu H, Hait WN, Yang JM (2003) Small interfering RNAinduced suppression of MDR1 (P-glycoprotein) restores sensitivity to multidrug-resistant cancer cells. Cancer Res 63:1515-1519

Xu J, Han F, Zhang X (2007) Silencing shrimp white spot syndrome virus (WSSV) genes by siRNA. Antiviral Res 73: 126-131

> Yague E, Higgins CF, Raguz S (2004) Complete reversal of multidrug resistance by stable expression of small interfering RNAs targeting MDR1. Gene Ther 11:1170-1174

> Yazawa R, Watanabe K, Koyama T, Ruangapan L, Tassanakajon A, Hirono I, Aoki T (2005) Development of gene transfer technology for black tiger shrimp, Penaeus monodon. J Exp Zool 303A:1104-1109

> Yodmuang S, Tirasophon W, Roshorm Y, Chinnirunvong W, Panyim S (2006) YHV-protease dsRNA inhibits YHV replication in Penaeus monodon and prevents mortality. Biochem Biophys Res Comm 341:351-356

Zhou N, Fang J, Mukhtar M, Acheampong E, Pomerantz RJ (2004) Inhibition of HIV-1 fusion with small interfering RNAs targeting the chemokine coreceptor CR4. Gene Ther 11:1703-1712

Submitted: April 27, 2009; Accepted: August 4, 2009 Proofs received from author(s): October 24, 2009 